\title{
The prognostic effect of LINC00152 for cancer: a meta-analysis
}

\author{
Fei-Yu Quan ${ }^{1, *}$, Jun Jiang ${ }^{2, *}$, Yi-Fan Zhai ${ }^{3, *}$, Bing Li ${ }^{2}$, Xin-Hua Wu ${ }^{4}$ and Wei Nie \\ ${ }^{1}$ The 425th Hospital of PLA, Sanya, Hainan, China \\ ${ }^{2}$ Department of Respiratory Medicine, Shanghai Changzheng Hospital, Second Military Medical University, Shanghai, China \\ ${ }^{3}$ Department of Respiratory Medicine, Eastern Hepatobiliary Surgery Hospital, Second Military Medical University, Shanghai, \\ China \\ ${ }^{4}$ Department of Internal Medicine, The 425th Hospital of PLA, Hainan, China \\ *These authors contributed equally to this work
}

Correspondence to: Bing Li, email: bing_li1962@163.com

Xin-Hua Wu, email: wuxinhuasy2016@163.com

Wei Nie, email: niewei-1001@163.com

Keywords: cancer, LINC00152, biomarker, OS

Received: July 12, 2017 Accepted: July 30, $2017 \quad$ Published: August 10, 2017

Copyright: Quan et al. This is an open-access article distributed under the terms of the Creative Commons Attribution License 3.0 (CC BY 3.0 ), which permits unrestricted use, distribution, and reproduction in any medium, provided the original author and source are credited.

\section{ABSTRACT}

No meta-analysis has been performed to evaluate the association between LINC00152 and the survival of patients with cancers. We thus carried out this study. The online databases, such as PubMed, EMBASE, and the Cochrane controlled trials register, were searched to identify relevant articles. Dichotomous data were analyzed using the odds ratio (OR) as the summary statistic. The association between LINC00152 and survival of cancer was analyzed by pooling the hazard ratio (HR) with its corresponding 95\% confidence interval (CI). Nine studies with 862 patients with cancer were included in this meta-analysis. The expression of LINC00152 was not associated with the age of patients $(\mathrm{OR}=0.79,95 \% \mathrm{CI}=0.55-1.14)$ and gender $(\mathrm{OR}$ $=1.08,95 \% \mathrm{CI}=0.74-1.58)$. However, we found significant positive associations between LINC00152 and lymph node metastasis (OR $=2.54,95 \% \mathrm{CI}=1.54-4.18$ ) and TNM stage $(O R=2.32,95 \% C I=1.36-3.93)$. Furthermore, the expression of LINC00152 was significantly associated with tumor recurrence (OR $=3.32,95 \%$ CI $=1.98-5.57)$ and shorter $\mathrm{OS}(H R=1.94,95 \% \mathrm{CI}=1.25-3.02)$. In conclusion, the results of this meta-analysis suggest that LINC00152 might be a biomarker for shorter OS and tumor recurrence in cancers.

\section{INTRODUCTION}

Long noncoding RNAs (lncRNAs) are defined as RNA transcripts of more than 200 nucleotides in length [1]. Many studies have suggested that IncRNAs were played an important role in tumorigenesis, proliferation, and metastasis in cancer development [2,3]. For example, Jiang et al. showed that lnc-epidermal growth factor receptor (EGFR) linked an immunosuppressive state to cancer by promoting Treg cell differentiation [4]. Koirala et al. demonstrates IncRNA AK023948 and DHX9 as important players in the AKT pathway, and that their upregulation may contribute to breast tumour progression [5]. Li et al. indicated that highly up-regulated in liver cancer (HULC) promotes the phosphorylation of Y-box binding protein 1 through the extracellular signalregulated kinase pathway, in turn regulates the interaction of YB-1 with certain oncogenic mRNAs [6]. However, the exact underlying molecular mechanism and the clinical implications of lncRNAs were still largely unknown.

Long intergenic non-coding RNA 00152 (LINC00152) was suggested to have oncogenic impacts on several cancers [7-15]. It is located on chromosome 2 p11.2, which has a transcript length of 828 nucleotides. Recently, Nötzold et al. found that cells depleted of LINC00152 arrested in prometa phase of mitosis and showed reduced Hela cell viability [16]. In RNA affinity purification (RAP) studies, the researchers indicated that LINC00152 interacted with a network of proteins which were associated with $\mathrm{M}$ phase of the cell cycle [16]. 
Chen et al. found that the expression of LINC00152 was significantly associated with tumor invasion depth, lymph node metastasis, and higher tumor-node-metastasis (TNM) stage in gastric cancer [11]. Another group also found that LINC00152 expression was correlated with higher TNM stage, larger tumor size, and lymph node metastasis in lung cancer [7]. In addition, Yu et al. suggested that the increased expression of LINC00152 was significantly correlated with T stage, N stage, TNM stage, and invasion in tongue squamous cell carcinoma [4]. Therefore, we supposed that LINC00152 might influence the survival of patients with cancers. However, no meta-analysis has been performed to evaluate the association between LINC00152 and the survival of patients with cancers. We thus carried out this study.

\section{RESULTS}

\section{Study characteristics}

Figure 1 showed the process of identifying relevant studies. Thirty-two studies were found in the initial search. After a detailed evaluation, 23 studies were excluded. Finally, 9 studies with 862 patients with cancer were included in this meta-analysis. Colorectal cancer, gastric cancer, renal cell carcinoma, gallbladder cancer, lung cancer, hepatocellular carcinoma, and tongue squamous cell carcinoma were investigated in the original studies. Table 1 showed the characteristics of the included studies. Only 4 studies could provide the data of overall survival (OS).

\section{Results of the meta-analysis}

The association between the expression of LINC00152 and clinicopathological parameters are shown in Table 2. As shown in Figure 2, the expression of LINC00152 was not associated with the age of patients $(\mathrm{OR}=0.79,95 \% \mathrm{CI}=0.55-1.14)$. In addition, no significant association was found between the expression of LINC00152 and gender $(\mathrm{OR}=1.08,95 \% \mathrm{CI}=$ 0.74-1.58; Figure 3). However, we found significant positive associations between LINC00152 and lymph node metastasis $(\mathrm{OR}=2.54,95 \% \mathrm{CI}=1.54-4.18$; Figure 4) and $\mathrm{TNM}$ stage $(\mathrm{OR}=2.32,95 \% \mathrm{CI}=1.36-3.93$; Figure 5). Furthermore, the expression of LINC00152 was significantly associated with tumor recurrence $(\mathrm{OR}=3.32$, $95 \% \mathrm{CI}=1.98-5.57$; Figure 6$)$ and shorter $\mathrm{OS}(\mathrm{HR}=1.94$, $95 \% \mathrm{CI}=1.25-3.02$; Figure 7 ).

\section{DISCUSSION}

Many evidence suggested that LINC00152 may participate in the carcinogenesis of cancers [17]. Thus, we conjectured that LINC00152 could change the prognosis of patients with cancers. To our knowledge, this was the first meta-analysis to evaluate the association between the expression of LINC00152 and clinicopathological parameters in cancers. In the present meta-analysis, we found that LINC00152 was significantly associated with lymph node metastasis and TNM stage. Chen et al. found that LINC00152 overexpression could facilitated gastric cancer cell proliferation by accelerating the cell cycle [14]. Cai et al. suggested that LINC00152 could promote cell migration, invasion and epithelialmesenchymal transition (EMT) progression in vitro [11]. Ji et al. found that LINC00152 could promote cell proliferation in vitro and tumor growth in vivo [18]. However, silencing LINC00152 can suppress the cell proliferation and invasion in hepatocellular carcinoma cells [8]. The mechanism investigation suggested that LINC00152 inhibited the E-cadherin expression via interacting with EZH2 and promoted the Epithelialmesenchymal transition (EMT) phenomenon in HCC cells [8]. These data might explain why the patients with high level of LINC00152 showed lymph node metastasis and TNM stage. Furthermore, we found significant positive associations between LINC00152 and tumor recurrence and shorter OS of patients with cancer. Thus, LINC00152 might be a potential biomarker in patients with cancer. The doctors should pay more attention to the cancer patients with high expression of LINC00152. However, Qiu did not found LINC00152 was a significant predictor of survival in colorectal cancer [16]. Thus, future studies with colorectal cancer patients are requested to determine this issue.

Some studies investigated the clinical implications of LINC00152 in cancers. Li et al. indicated that plasma levels of HULC and LINC00152 could be used to diagnose hepatocellular carcinoma [19]. Yang and colleagues suggested that serum H19 and LINC00152 might be potential biomarkers for diagnosis of gastric cancer [20]. Yue et al. found that LINC00152 might be a prognostic indicator of oxaliplatin responsiveness in colon cancer patients [21]. In this study, we found that LINC00152 may be a biomarker of the prognosis of cancers. Thus, detecting of LINC00152 might help doctors to manage their patients.

Some limitations of this meta-analysis should be acknowledged. First, only 4 studies could provide the survival data and only 1 study could provide the diseasefree survival data. The sample size recruited in the analysis of overall survival was too small, which could not provide statistical power to make significant conclusion. Second, no study from other countries was included in our study. Third, only studies which were indexed by the selected databases were included for data analysis. Fourth, biomarkers are specific for different cancer types or cancer subtypes, especially for LncRNA, because many LncRNAs function in a cell-type-specific way [18]. However, we could not perform a subgroup analysis in a specific cancer or according to the ethnicity due to limited 
Table 1: Characteristics of the included studies

\begin{tabular}{|c|c|c|c|c|c|c|c|c|}
\hline $\begin{array}{c}\text { First } \\
\text { author }\end{array}$ & Year & $\begin{array}{c}\text { Gender } \\
\text { (male/female) }\end{array}$ & Site of cancer & $\begin{array}{l}\text { Tumor } \\
\text { Stage }\end{array}$ & $\begin{array}{c}\text { Samle } \\
\text { size }\end{array}$ & Outcome & Co-variants & NOS \\
\hline Qiu & 2015 & NA & Colorectal cancer & II-III & 160 & OS & No & 7 \\
\hline Chen & 2016 & $69 / 28$ & Gastric cancer & I-IV & 97 & OS & $\begin{array}{l}\text { Tumor invasion depth, Lymphatic } \\
\text { metastasis, TNM stage }\end{array}$ & 8 \\
\hline $\mathrm{Wu}$ & 2016 & $48 / 29$ & Renal cell carcinoma & I-III & 77 & OS & TNM stage, Fuhrman grade & 8 \\
\hline Yue & 2016 & $65 / 69$ & Colorectal cancer & II-III & 134 & OS, DFS & TNM stage, AJCC stage & 8 \\
\hline Cai & 2017 & $9 / 26$ & Gallbladder cancer & I-IV & 35 & OS* & NA & 6 \\
\hline Chen & 2017 & $24 / 36$ & Lung cancer & I-III & 60 & OS* & NA & 8 \\
\hline Deng & 2017 & $14 / 58$ & Hepatocellular carcinoma & I-IV & 72 & OS* & NA & 7 \\
\hline Wang & 2017 & $27 / 18$ & Renal cell carcinoma & I-IV & 45 & OS* & NA & 6 \\
\hline $\mathrm{Yu}$ & 2017 & NA & $\begin{array}{l}\text { Tongue squamous cell } \\
\text { carcinoma }\end{array}$ & I-IV & 182 & OS* & NA & 6 \\
\hline
\end{tabular}

DFS, disease-free survival; OS, overall survival; NOS, Newcastle-Ottawa Scale; NA, not available.

* no data of OS could be extracted.

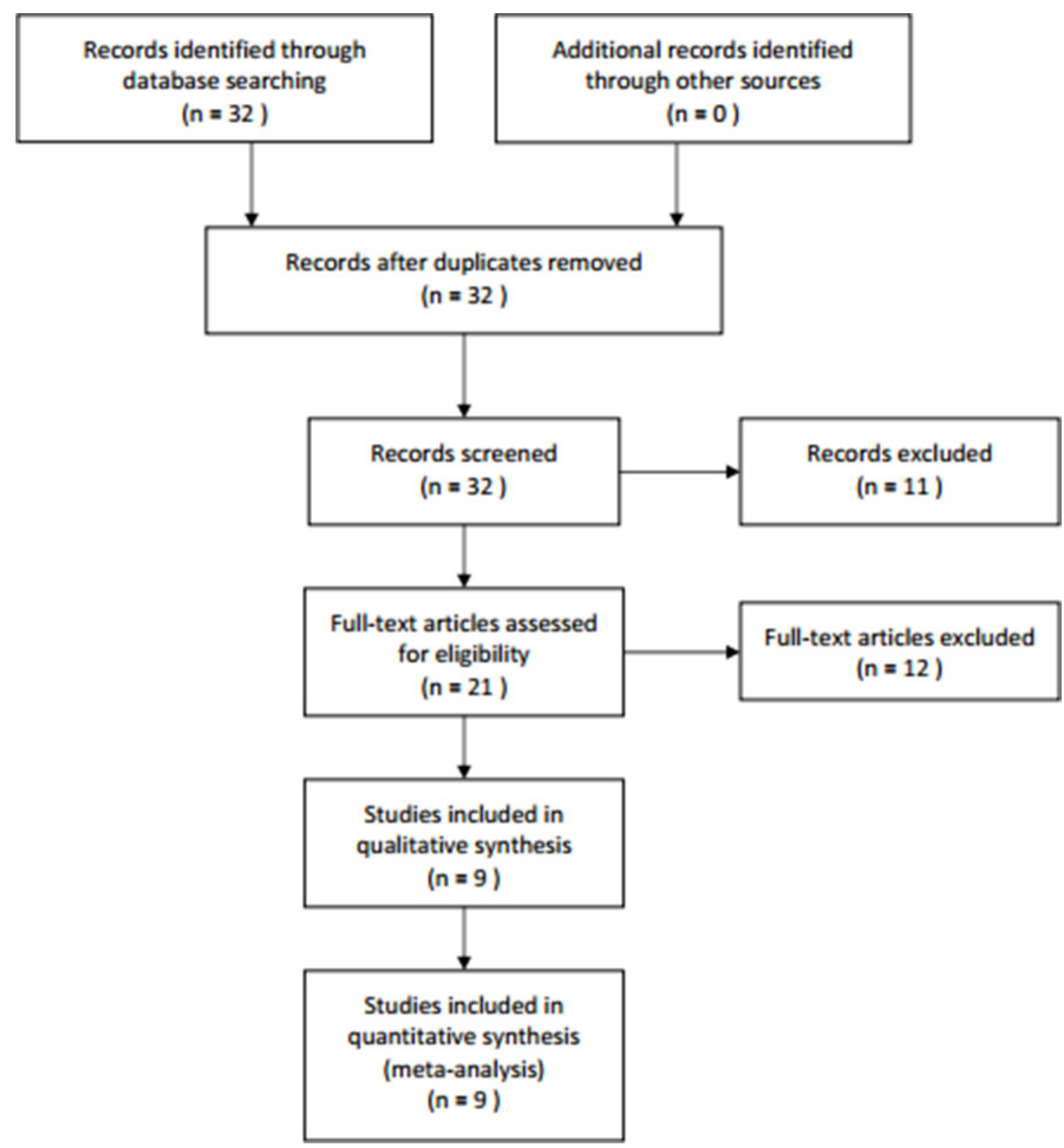

Figure 1: Flow diagram of study identification. 
Table 2: The association between LINC00152 and clinicopathological parameters

\begin{tabular}{lcccc}
\hline & Test of association & \multicolumn{2}{c}{ Heterogeneity } \\
\cline { 2 - 5 } & OR/HR (95\% CI) & $\boldsymbol{P}$ Value & $\mathbf{I}^{\mathbf{2}} \mathbf{( \% )}$ & $\boldsymbol{P}$ Value \\
\hline Age & $0.79(0.55-1.14)$ & 0.21 & 0 & 0.53 \\
Gender & $1.08(0.74-1.58)$ & 0.70 & 0 & 0.76 \\
Lymph node metastasis & $2.54(1.54-4.18)$ & 0.0003 & 37 & 0.16 \\
TNM stage & $2.32(1.36-3.93)$ & 0.002 & 52 & 0.04 \\
Tumor recurrence & $3.32(1.98-5.57)$ & $<0.00001$ & 0 & 0.45 \\
OS & $1.94(1.25-3.02)$ & 0.003 & 50 & 0.11 \\
\hline
\end{tabular}

OS, overall survival; HR, hazard ratio; OR, odds ratio; CI, confidence interval.

data. We also could not do an in vitro experiment. Thus, more studies from other countries are needed to confirm the results from this meta-analysis.

In conclusion, the results of this meta-analysis suggest that LINC00152 might be a biomarker for shorter $\mathrm{OS}$ and tumor recurrence in cancers.

\section{MATERIALS AND METHODS}

\section{Publication search}

The online databases, such as PubMed, EMBASE, and the Cochrane controlled trials register, were searched

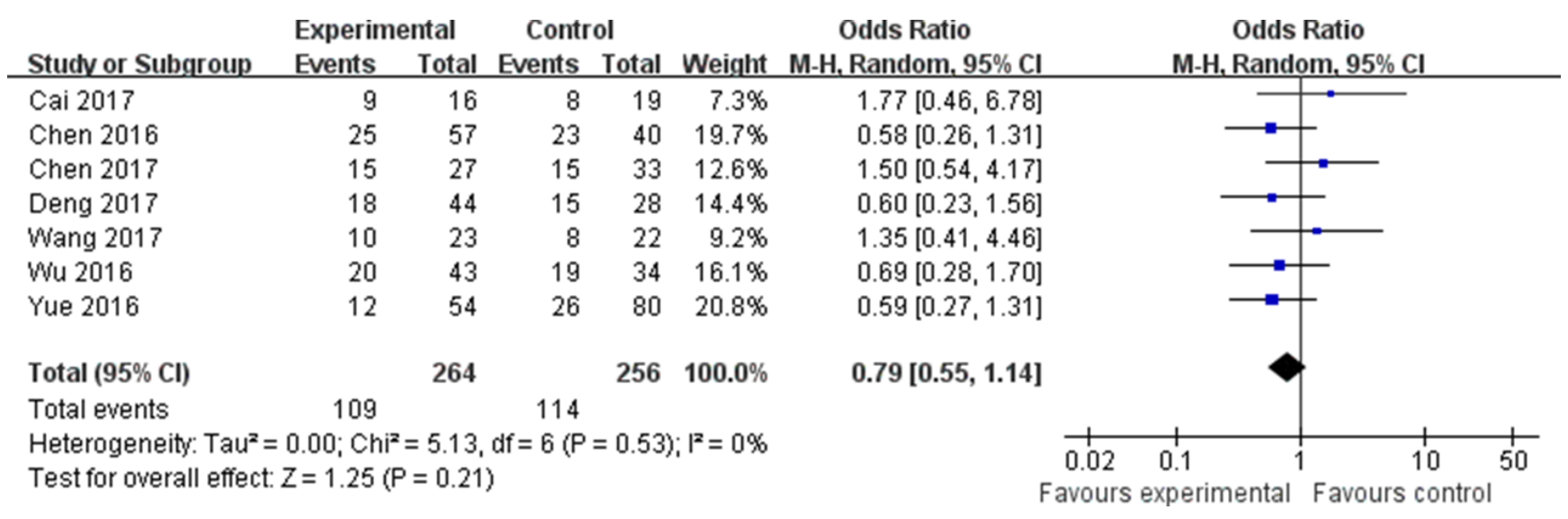

Figure 2: Forest plot (random effects model) describing the association of the LINC00152 with age of patients. The expression of LINC00152 was not associated with the age of patients.

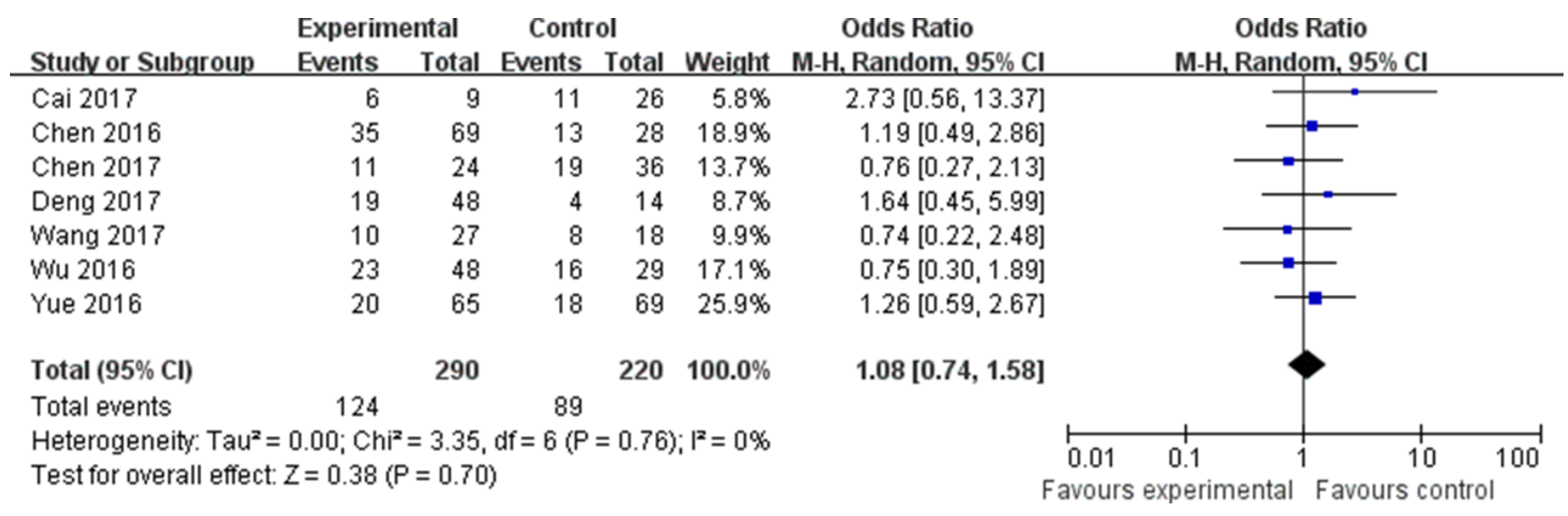

Figure 3: Forest plot (random effects model) describing the association of the LINC00152 with gender of patients. The expression of LINC00152 was not associated with the gender of patients. 


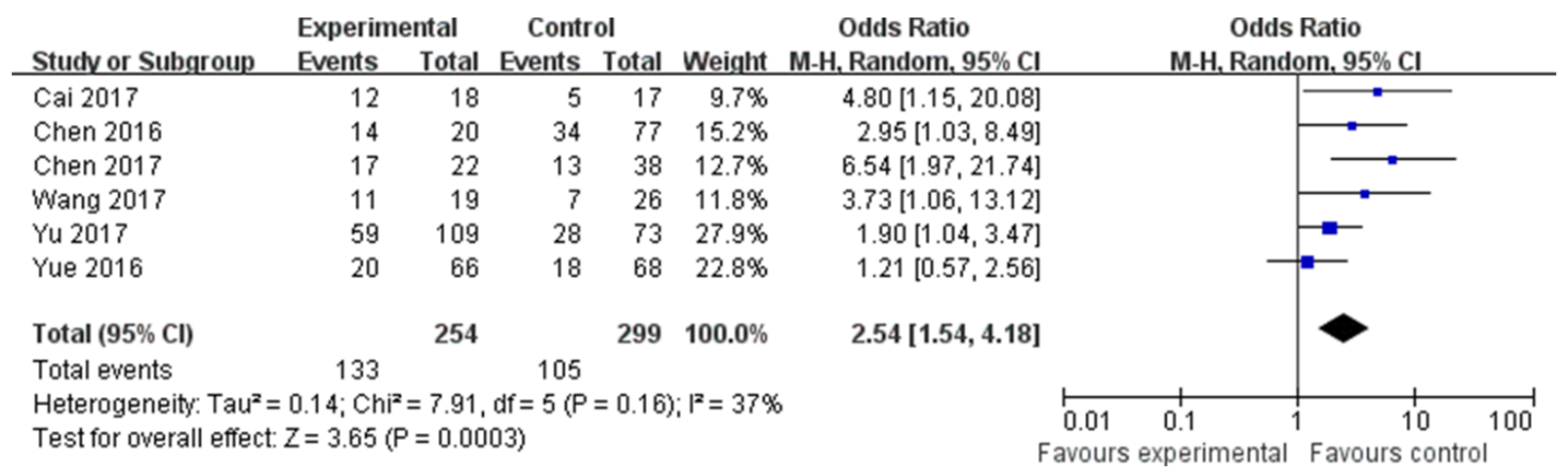

Figure 4: Forest plot (random effects model) describing the association of the LINC00152 with lymph node metastasis. The expression of LINC00152 was significantly associated with the lymph node metastasis.

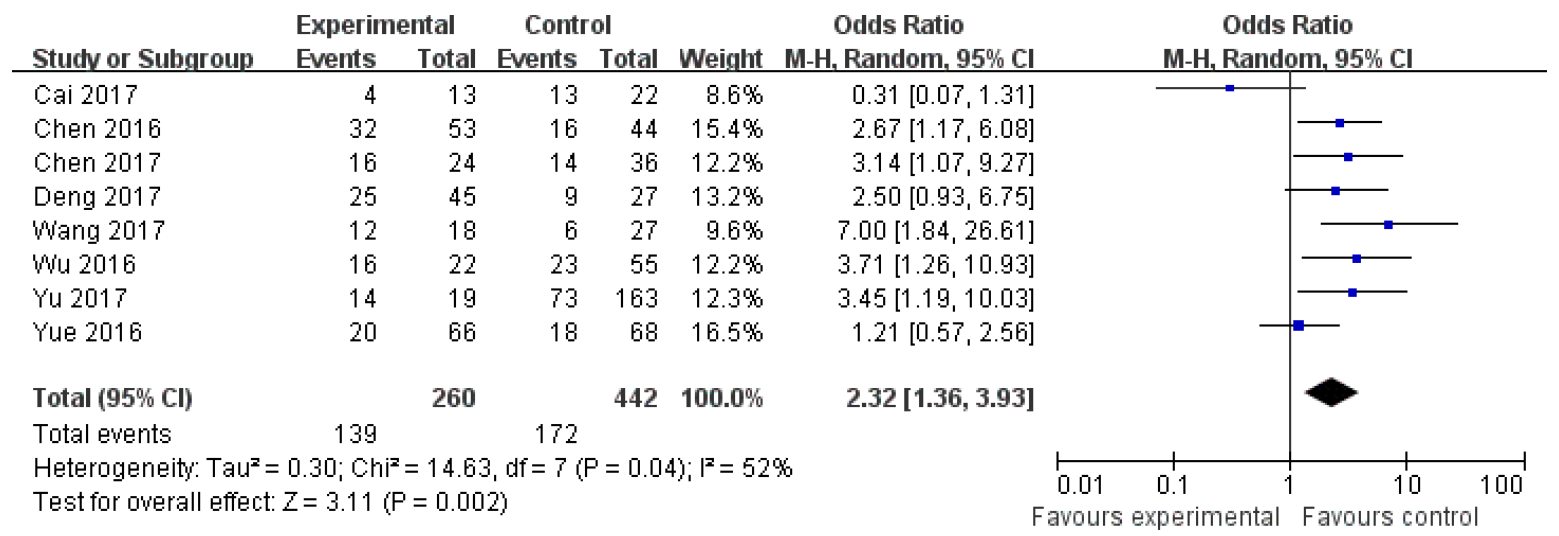

Figure 5: Forest plot (random effects model) describing the association of the LINC00152 with TNM stage. The expression of LINC00152 was significantly associated with TNM stage.

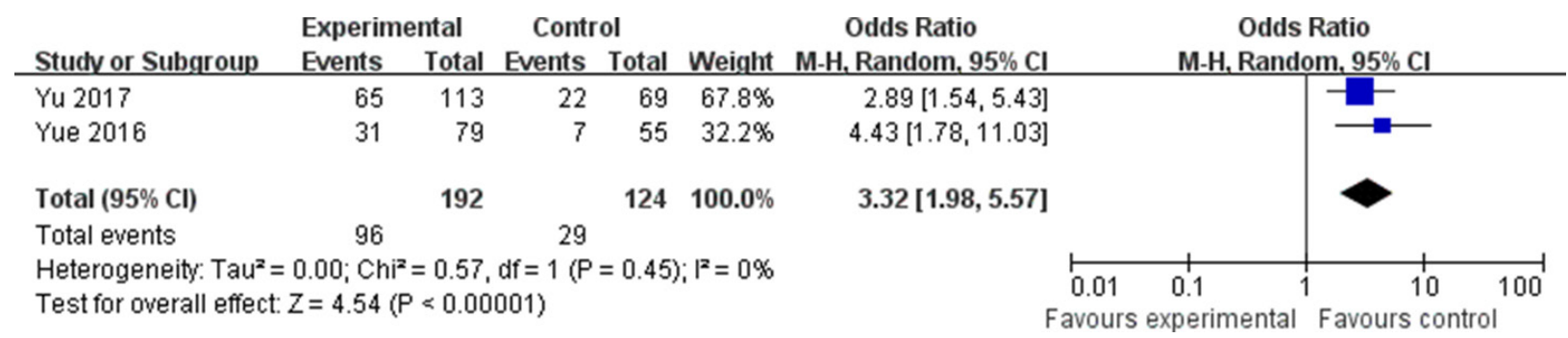

Figure 6: Forest plot (random effects model) describing the association of the LINC00152 with tumor recurrence. The expression of LINC00152 was significantly associated with tumor recurrence.

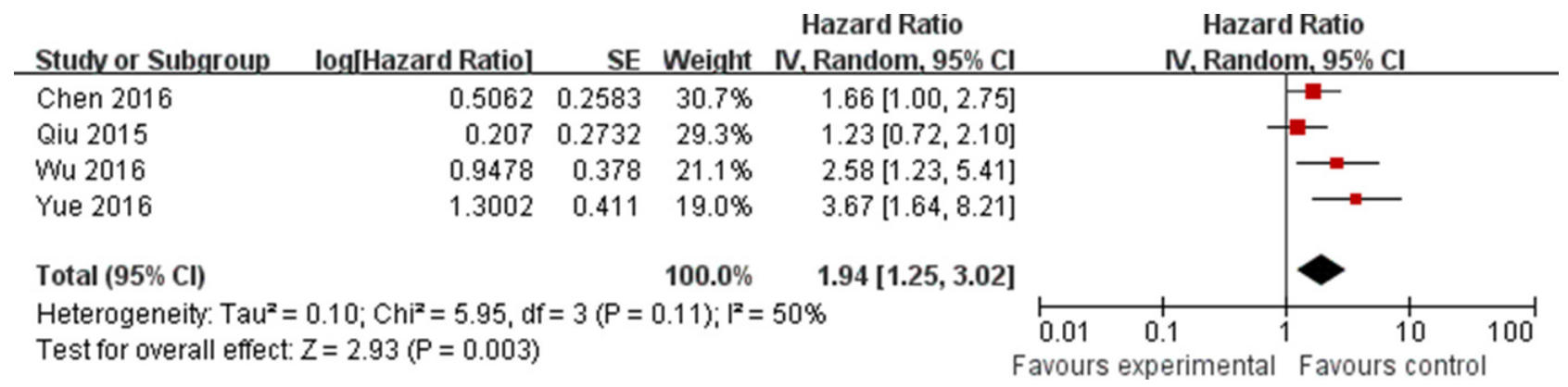

Figure 7: Forest plot (random effects model) describing the association of the LINC00152 with overall survival of cancer. The expression of LINC00152 was significantly associated with overall survival of cancer. 
to identify relevant articles published up to MAY 2017 in any language. The electronic search included the terms: LINC00152 and "cancer or carcinoma or neoplasm or tumor". We also reviewed the reference lists of original reports and reviews. Country was not restricted in this search.

\section{Inclusion and exclusion criteria}

The included studies should meet the following criteria: (1) the study should assessed the association between LINC00152 and the clinicopathological parameters of cancers; (2) cancer should be diagnosed according to histopathological evaluation. The study should be excluded: (1) the study was relevant to cancer or LINC00152; (2) the study was an animal study; (3) the study was a review or abstract.

\section{Data extraction and quality assessment}

Two authors reviewed and extracted the data from original studies independently. The following data were extracted: the first author's name, year, gender of the patient, site of cancer, tumor stage, sample size, outcome, and co-variants. We used the Newcastle-Ottawa Scale (NOS) to assess the methodological quality of included studies [22].

\section{Statistical analysis}

Dichotomous data were analyzed using the odds ratio (OR) as the summary statistic. The association between LINC00152 and survival of cancer was analyzed by pooling the HR with its corresponding 95\% CI. The heterogeneity investigted by using the chi-squared based Q-statistic test. The random-effects model was used to analyze the pooled HRs. If the number of included studies was more than 10, funnel plot was used to analyze the publication bias. All the $P$-values were determined by a 2-sided test. All statistical analyses were conducted using RevMan 5.1 software (Nordic Cochrane Center, Copenhagen, Denmark).

\section{ACKNOWLEDGMENTS AND FUNDING}

This work was supported by the National Natural Science Foundation of China (No.81172227, No. 81601988), the Research Foundation of Shanghai Municipal Education Commission (No.12ZZ073), the Shanghai Natural Science Foundation (No.16ZR1428900), and the Shanghai Municipal Commission of Health and Family Planning (No. 201440398).

\section{CONFLICTS OF INTEREST}

None.

\section{REFERENCES}

1. Kapranov P, Cheng J, Dike S, Nix DA, Duttagupta R, Willingham AT, Stadler PF, Hertel J, Hackermüller J, Hofacker IL, Bell I, Cheung E, Drenkow J, et al. RNA maps reveal new RNA classes and a possible function for pervasive transcription. Science. 2007; 316:1484-8.

2. Nie W, Ge HJ, Yang XQ, Sun X, Huang H, Tao X, Chen WS, Li B. LncRNA-UCAl exerts oncogenic functions in non-small cell lung cancer by targeting miR-193a-3p. Cancer Lett. 2016; 371:99-106.

3. Hong HH, Hou LK, Pan X, Wu CY, Huang H, Li B, Nie $\mathrm{W}$. Long non-coding RNA UCA1 is a predictive biomarker of cancer. Oncotarget. 2016; 7:57991-58000. https://doi. org/10.18632/oncotarget.10142.

4. Jiang R, Tang J, Chen Y, Deng L, Ji J, Xie Y, Wang K, Jia W, Chu WM, Sun B. The long noncoding RNA lnc-EGFR stimulates T-regulatory cells differentiation thus promoting hepatocellular carcinoma immune evasion. Nat Commun. 2017; 8:15129.

5. Koirala P, Huang J, Ho TT, Wu F, Ding X, Mo YY. LncRNA AK023948 is a positive regulator of AKT. Nat Commun. 2017; 8:14422.

6. Li D, Liu X, Zhou J, Hu J, Zhang D, Liu J, Qiao Y, Zhan Q. Long noncoding RNA HULC modulates the phosphorylation of YB-1 through serving as a scaffold of extracellular signal-regulated kinase and YB-1 to enhance hepatocarcinogenesis. Hepatology. 2017; 65:1612-1627.

7. Yu J, Liu Y, Guo C, Zhang S, Gong Z, Tang Y, Yang L, He Y, Lian Y, Li X, Deng H, Liao Q, Li X, et al. Upregulated long non-coding RNA LINC00152 expression is associated with progression and poor prognosis of tongue squamous cell carcinoma. J Cancer. 2017; 8:523-530.

8. Deng X, Zhao XF, Liang XQ, Chen R, Pan YF, Liang J. LINC00152 promotes cancer progression in hepatitis $\mathrm{B}$ virus-associated hepatocellular carcinoma. Biomed Pharmacother. 2017; 90:100-108.

9. Wang Y, Liu J, Bai H, Dang Y, Lv P, Wu S. Long intergenic non-coding RNA 00152 promotes renal cell carcinoma progression by epigenetically suppressing P16 and negatively regulates miR-205. Am J Cancer Res. 2017; 7:312-322.

10. Chen QN, Chen X, Chen ZY, Nie FQ, Wei CC, Ma HW, Wan L, Yan S, Ren SN, Wang ZX. Long intergenic noncoding RNA 00152 promotes lung adenocarcinoma proliferation via interacting with EZH2 and repressing IL24 expression. Mol Cancer. 2017; 16:17.

11. Cai Q, Wang Z, Wang S, Weng M, Zhou D, Li C, Wang J, Chen E, Quan Z. Long non-coding RNA LINC00152 promotes gallbladder cancer metastasis and epithelialmesenchymal transition by regulating HIF-1 $\alpha$ via miR-138. Open Biol. 2017; 7:160247.

12. Yue B, Cai D, Liu C, Fang C, Yan D. LINC00152 Functions as a Competing Endogenous RNA to Confer Oxaliplatin Resistance and Holds Prognostic Values in Colon Cancer. Mol Ther. 2016; 24:2064-2077. 
13. Wu Y, Tan C, Weng WW, Deng Y, Zhang QY, Yang XQ, Gan HL, Wang T, Zhang PP, Xu MD, Wang YQ, Wang CF. Long non-coding RNA LINC00152 is a positive prognostic factor for and demonstrates malignant biological behavior in clear cell renal cell carcinoma. Am J Cancer Res. 2016; 6:285-99.

14. Chen WM, Huang MD, Sun DP, Kong R, Xu TP, Xia R, Zhang EB, Shu YQ. Long intergenic non-coding RNA 00152 promotes tumor cell cycle progression by binding to EZH2 and repressing p15 and p21 in gastric cancer. Oncotarget. 2016; 7:9773-87. https://doi.org/10.18632/ oncotarget.6949.

15. Qiu JJ, Yan JB. Long non-coding RNA LINC01296 is a potential prognostic biomarker in patients with colorectal cancer. Tumour Biol. 2015; 36:7175-83.

16. Nötzold L, Frank L, Gandhi M, Polycarpou-Schwarz M, Groß M, Gunkel M, Beil N, Erfle H, Harder N, Rohr K, Trendel J, Krijgsveld J, Longerich T, et al. The long non-coding RNA LINC00152 is essential for cell cycle progression through mitosis in HeLa cells. Sci Rep. 2017; 7:2265.

17. Yu Y, Yang J, Li Q, Xu B, Lian Y, Miao L. LINC00152: A pivotal oncogenic long non-coding RNA in human cancers. Cell Prolif. 2017 May 2. https://doi.org/10.1111/cpr.12349. [Epub ahead of print].
18. Li J, Wang X, Tang J, Jiang R, Zhang W, Ji J, Sun B. HULC and LINC00152 Act as Novel Biomarkers in Predicting Diagnosis of Hepatocellular Carcinoma. Cell Physiol Biochem. 2015; 37:687-96.

19. Ji J, Tang J, Deng L, Xie Y, Jiang R, Li G, Sun B. LINC00152 promotes proliferation in hepatocellular carcinoma by targeting EpCAM via the mTOR signaling pathway. Oncotarget. 2015; 6:42813-24. https://doi. org/10.18632/oncotarget.5970.

20. Yang T, Zeng H, Chen W, Zheng R, Zhang Y, Li Z, Qi J, Wang M, Chen T, Lou J, Lu L, Zhou T, Dai S, et al. Helicobacter pylori infection, H19 and LINC00152 expression in serum and risk of gastric cancer in a Chinese population. Cancer Epidemiol. 2016; 44:147-153.

21. Liu SJ, Horlbeck MA, Cho SW, Birk HS, Malatesta M, He D, Attenello FJ, Villalta JE, Cho MY, Chen Y, Mandegar MA, Olvera MP, Gilbert LA, et al. CRISPRi-based genomescale identification of functional long noncoding RNA loci in human cells. Science. 2017; 355.

22. Wells GA, Shea B, O'Connell D, Peterson J, Welch V, Losos M, Tugwell P. The Newcastle-Ottawa Scale (NOS) for assessing the quality of non-randomised studies in meta-analyses. URL:http://www.ohri.ca/programs/clinical_ epidemiology/oxford.asp. 